\title{
The emergence of long timescales and stereotyped behaviors in C. elegans
}

\author{
Greg J Stephens ${ }^{1 *}$, Matthew Bueno de Mesquita ${ }^{2}$, William S Ryu², William Bialek ${ }^{1,3}$ \\ From Twentieth Annual Computational Neuroscience Meeting: CNS*2011 \\ Stockholm, Sweden. 23-28 July 2011
}

Animal behaviors are often decomposable into discrete, stereotyped elements, well-separated in time. In one model, such behaviors are triggered by specific commands; in the extreme case, the discreteness of behavior is traced to the discreteness of action potentials in the individual command neurons. Here, we use the crawling behavior of the nematode $C$. elegans to demonstrate the opposite view, in which discreteness, stereotypy and long timescales emerge from the collective dynamics of the behavior itself. In previous work [1], we found that as C. elegans crawls, its body moves through a "shape space" in which four dimensions capture $~ 95 \%$ of the variance in body shape. Here we show that stochastic dynamics within this shape space predicts transitions between attractors corresponding to abrupt reversals in crawling direction. With no free parameters, our inferred stochastic dynamical system generates reversal time scales and stereotyped trajectories in close agreement with experimental observations. We use the stochastic dynamics to show that the noise amplitude decreases systematically with increasing time away from food, resulting in longer bouts of forward crawling and suggesting that worms can use noise to adaptive benefit.

\section{Reference}

1. Stephens GJ, Johnson-Kerner B, Bialek W, Ryu WS: Dimensionality and dynamics in the behavior of C. elegans. PLOS Comp Bio 2008, 4:e1000028.

\section{doi:10.1186/1471-2202-12-S1-P13}

Cite this article as: Stephens et al:: The emergence of long timescales and stereotyped behaviors in C. elegans. BMC Neuroscience 2011 12(Suppl 1):P13.

\footnotetext{
* Correspondence: gstephen@princeton.edu

'Lewis-Sigler Institute for Integrative Genomics and Physics Department,

Princeton University, Princeton, NJ 08544, USA

Full list of author information is available at the end of the article
}

Submit your next manuscript to BioMed Central and take full advantage of:

- Convenient online submission

- Thorough peer review

- No space constraints or color figure charges

- Immediate publication on acceptance

- Inclusion in PubMed, CAS, Scopus and Google Scholar

- Research which is freely available for redistribution

Submit your manuscript at www.biomedcentral.com/submit
() Biomed Central
C Biomed Central

() 2011 Stephens et al; licensee BioMed Central Ltd. This is an open access article distributed under the terms of the Creative Commons Attribution License (http://creativecommons.org/licenses/by/2.0), which permits unrestricted use, distribution, and reproduction in any medium, provided the original work is properly cited. 